\title{
Pharmacologic preconditioning of JTE-607, a novel cytokine inhibitor, attenuates ischemia-reperfusion injury in the myocardium
}

\author{
Masahiro Ryugo, MD \\ Yoshiki Sawa, MD \\ Masamichi Ono, MD \\ Yuji Miyamoto, MD \\ Alexei N. Aleshin, MD \\ Hikaru Matsuda, MD
}

From the Division of Cardiovascular Surgery, Department of Surgery, Osaka University Graduate School of Medicine, Osaka, Japan.

Received for publication April 28, 2003; revisions requested July 30, 2003; accepted for publication Aug 11, 2003.

Address for reprints: Yoshiki Sawa, MD, Division of Cardiovascular Surgery, Department of Surgery, Osaka University Graduate School of Medicine, 2-2 Yamadaoka, Suita, Osaka 565-0871, Japan (E-mail: sawa@surg1.med.osaka-u.ac.jp).

J Thorac Cardiovasc Surg 2004;127:1723-7 $0022-5223 / \$ 30.00$

Copyright () 2004 by The American Association for Thoracic Surgery

doi:10.1016/j.jtcvs.2003.08.015
Background: Myocardial ischemia-reperfusion injury is a main cause of postoperative cardiac dysfunction, and a burst of proinflammatory cytokines, such as tumor necrosis factor $\alpha$, interleukin $1 \beta$, interleukin 6 , and interleukin 8 , plays a pivotal role. Recently, JTE- 607 has been reported as a potent inhibitor of the multiple inflammatory cytokines in the endotoxin shock mouse model. In this study we proved the hypothesis that JTE-607 might attenuate myocardial ischemia-reperfusion injury in a rat model.

Methods: The isolated rat hearts in the JTE- 607 preconditioning group ( $\mathrm{J}$ group, $\mathrm{n}$ $=8)$ or control group $(\mathrm{C}$ group, $\mathrm{n}=8)$ were subjected to warm ischemia $\left(37^{\circ} \mathrm{C}\right)$ for 30 minutes, followed by 60 minutes of reperfusion with the Langendorff perfusion system.

Results: Left ventricular developed pressure and maximum dp/dt after reperfusion were significantly improved in the $\mathrm{J}$ group than in the $\mathrm{C}$ group $(P<.01)$. Creatine phosphokinase leakage is significantly lower in the $\mathrm{J}$ group $(P<.05)$. Moreover, the tissue cytokine levels, such as tumor necrosis factor $\alpha$, interleukin 6, and interleukin 8 , in the myocardium were significantly lower in the $\mathrm{J}$ group than in the $\mathrm{C}$ group $(P$ $<.05)$.

Conclusion: These results suggested that the pharmacologic preconditioning of JTE-607 inhibits a burst of endogenous cytokines in the myocardium, resulting in the improvement of cardiac function after ischemia-reperfusion injury. Thus JTE607 might be a novel therapeutic strategy for the protection of postoperative cardiac dysfunction in cardiac surgery.

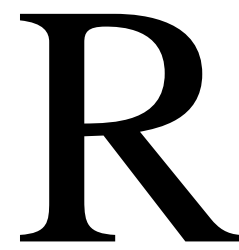

ecent advances in myocardial protection have improved the clinical results in cardiac surgery. However, severely critical cases associated with a compromised heart, such as a failing heart or postischemic conditions, still occur, and thus further attempts to improve myocardial protection should be addressed. ${ }^{1}$

Recent studies have shown that proinflammatory cytokines (tumor necrosis factor [TNF] $\alpha$, interleukin [IL] $1 \beta$, IL-6, and IL-8) induced by ischemia-reperfusion injury lead to myocardial dysfunction, either directly or through the adherence of neutrophils to endothelial cells. ${ }^{2,3}$ Therefore several studies to attenuate cytokineinduced ischemia-reperfusion injury have been reported. However, no studies have reported inhibition for the broad spectrum of inflammatory cytokines, and few attempts at chronic application have been made. ${ }^{4}$ 

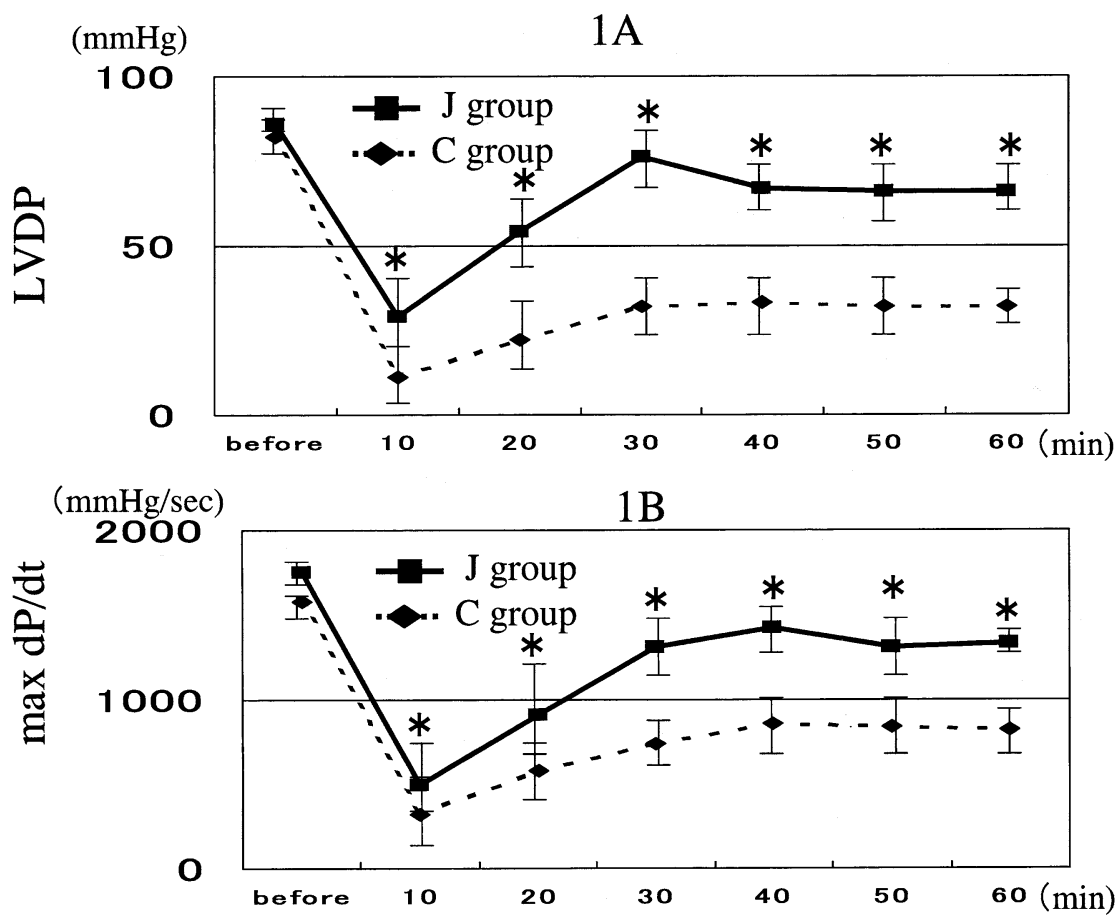

Figure 1. Cardiac function before and after ischemia. A, LVDP before and after ischemia. Better recovery of LVDP after ischemia was shown in the $\mathrm{J}$ group than in the $\mathrm{C}$ group. B, Maximum $\mathrm{dP} / \mathrm{dt}$ before and after ischemia. Better recovery of maximum $\mathrm{dP} / \mathrm{dt}$ after ischemia was shown in the $\mathrm{J}$ group than in the $\mathrm{C}$ group. ${ }^{*} P<.05, \mathrm{n}=8$ in each group. All values are expressed as means \pm SEM.

JTE-607, an N-benzoyl-L-phenylalanine-derived compound, is a multiple-cytokine inhibitor that strongly suppresses production of proinflammatory cytokines, such as IL-8, IL-1 $\beta$, and TNF- $\alpha$ from lipopolysaccharide (LPS)stimulated peripheral blood mononuclear cells by reducing the increase in the level of mRNAs of these cytokines. ${ }^{5}$ Although the activity is 100 to 1000 times lower in rodents compared with in human subjects, JTE-607 protects mice from LPS-induced endotoxin shock in accordance with a decrease in plasma TNF- $\alpha$ levels and also protects against LPS-induced acute lung injury through chemotactic cytokine inhibition, such as cytokine-induced neutrophil chemoattractant (CINC-1) from alveolar macrophages. ${ }^{6}$ Moreover, JTE-607 can be immediately absorbed by almost every organ, including the heart, by means of intravenous or intraperitoneal injection, and the half-life is about $30 \mathrm{~min}-$ utes. Therefore this drug is suited for preconditioning of the heart subjected to ischemia and reperfusion. Therefore it is expected that pharmacologic preconditioning with JTE-607 might attenuate ischemia-reperfusion injury in the myocardium by suppressing the production of inflammatory cytokines in a preclinical trial.

In this study we investigated whether the pharmacologic preconditioning of JTE-607 might attenuate ischemia-reperfusion injury in an isolated rat heart model.

\section{Methods}

\section{Test Compounds}

JTE-607, (-)-ethyl-N-\{3-5-dichloro-2-hydroxy-4-[2-(4-methylpiperazin-1-yl)]ethoxybenzoyl $\}$-L-phenylalanine dihydrochloride, was provided by Japan Tobacco, Osaka, Japan. JTE-607 was dissolved and diluted in 5\% mannitol before use.

\section{Pharmacologic Preconditioning and Rat Ischemia Model}

Sixteen Sprague-Dawley rats $(300 \mathrm{~g}$, male) were used for this study. Humane animal care complied with the "Principle of Laboratory Animal Care" formulated by the National Society for Medical Research and the "Guide for the Care and Use of Laboratory Animals" prepared by the Institute of Laboratory Animal Resources and published by the National Institutes of Health (National Institutes of Health publication No. 85-23, revised 1996). The rats were divided into the control group (C group, $\mathrm{n}=$ 8 ) and the JTE group (J group, $\mathrm{n}=8$ ). All rats were anesthetized by means of intraperitoneal injection of sodium pentobarbital (50 $\mathrm{mg} / \mathrm{kg}$ ), and $0.5 \mathrm{~mL}$ of saline (C group) or $0.1 \mathrm{mg} / \mathrm{kg}$ of JTE- 607 dissolved in the same volume of 5\% mannitol (J group) was injected intraperitoneally. Ten minutes after the injection and anticoagulation with heparin (200 USP units, intraperitoneally), the hearts were quickly excised in Krebs-Henseleit buffer (120.0 $\mathrm{mmol} / \mathrm{L} \mathrm{NaCl}, 4.5 \mathrm{mmol} / \mathrm{L} \mathrm{KCl}, 20.0 \mathrm{mmol} / \mathrm{L} \mathrm{NaHCO}{ }_{3}, 1.2$ $\mathrm{mmol} / \mathrm{L} \mathrm{KH}_{2} \mathrm{PO}_{4}, 1.2 \mathrm{mmol} / \mathrm{L} \mathrm{MgCl}_{2}, 2.5 \mathrm{mmol} / \mathrm{L} \mathrm{CaCl}_{2}$, and $10.0 \mathrm{mmol} / \mathrm{L}$ glucose gassed with $95 \% \mathrm{O}_{2}+5 \% \mathrm{CO}_{2}$ to obtain a 
$\mathrm{pH}$ of 7.4 at $37^{\circ} \mathrm{C}$ ) at a pressure equal to $1 \mathrm{~m}$ of $\mathrm{H}_{2} \mathrm{O}$ by means of a Langendorff apparatus. A thin-wall latex balloon was inserted into the left ventricle through the left atrium to monitor left ventricular pressure and to control left ventricular volume. After stabilization, heart rate, left ventricular developed pressure (LVDP), maximum dp/dt, and coronary flow were measured, with left ventricular diastolic pressure stabilized at $10 \mathrm{~mm} \mathrm{Hg}$. The hearts were then subjected to global ischemia at $37^{\circ} \mathrm{C}$ for 30 minutes, followed by 60 minutes of reperfusion. The balloon was deflated during ischemia, and the hearts were not paced during reperfusion. The indices of cardiac function were continuously measured after reperfusion and analyzed (Polygraph System, Nihon Kouden, Japan). The coronary effluent was collected in chilled vials to measure creatine phosphokinase (CPK) levels after reperfusion.

After 60 minutes of reperfusion, frozen sections of the hearts were made and stored at $-80^{\circ} \mathrm{C}$ for further assessment.

\section{Myocardial Water Content}

The basal region of the heart was taken and weighed to evaluate myocardial water content after reperfusion. Next, it was desiccated at $96^{\circ} \mathrm{C}$ for 24 hours and then reweighed. The myocardial water content was calculated by using the following formula: Myocardial water content $=(1-$ dry weight/wet weight $) \times 100(\%)$.

\section{Enzyme-Linked Immunosorbent Assay for Inflammatory Cytokines}

After 60 minutes of reperfusion, the frozen tissue samples were homogenized with a Polytron homogenizer (Brinkmann Instruments, Westbury, NY) and centrifuged. The concentration of tissue inflammatory cytokines was measured with enzyme-linked immunosorbent assay kits (TNF- $\alpha$, IL-1 $\beta$, and IL-6: Biosource International, Camarillo, Calif; IL-8: Immuno-Biological Laboratories, Gunma, Japan), according to the manufacturer's recommendation.

\section{Statistical Analysis}

All data are expressed as means \pm SEM. The differences in the data on functional recoveries were determined with 1-way repeated-measures analysis of variance, and those on CPK leakage and tissue cytokine concentrations were determined with the unpaired Student $t$ test.

\section{Results}

\section{Recovery of Cardiac Function After Global Ischemia}

Cardiac function was analyzed before and after global warm ischemia and reperfusion. In this experiment no significant differences in heart rate, LVDP, maximum $\mathrm{dp} / \mathrm{dt}$, or coronary flow were seen before global ischemia in the 2 groups.

The time course of percentage recovery of LVDP and maximum $\mathrm{dP} / \mathrm{dt}$ after global ischemia $\left(37^{\circ} \mathrm{C}\right.$ for 30 minutes $)$ was shown in Figure 1. The hearts of the $\mathrm{J}$ group showed significantly better recoveries of LVDP or maximum $\mathrm{dP} / \mathrm{dt}$ than the $\mathrm{C}$ group. The peak values of the recovery rate of LVDP and maximum $\mathrm{dP} / \mathrm{dt}$ were $79 \% \pm 5 \%$ and $80 \% \pm$ $4 \%$ in the $\mathrm{J}$ group and $39 \% \pm 6 \%$ and $54 \% \pm 7 \%$ in the $\mathrm{C}$ group $(P<.05)$.

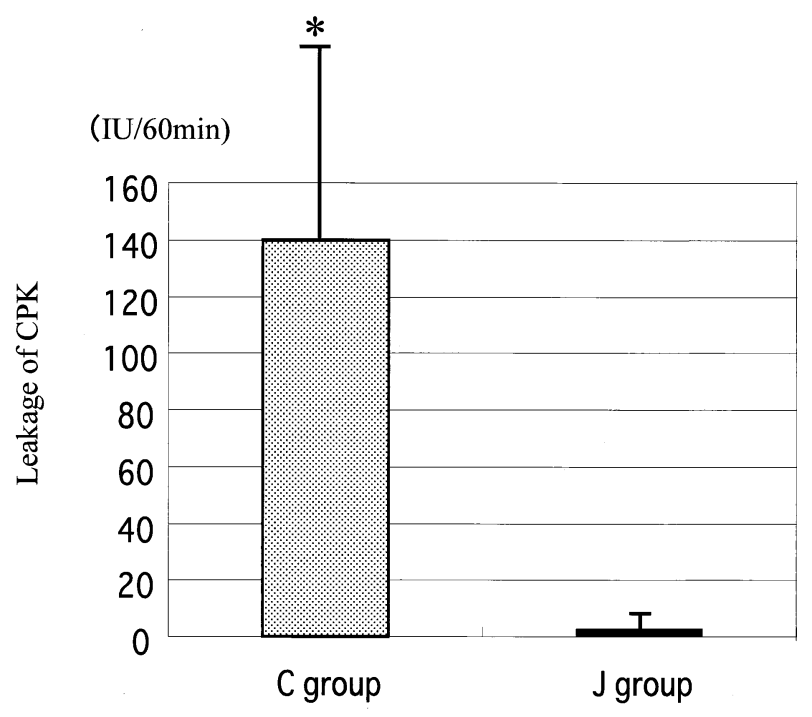

Figure 2. Suppression of leakage of CPK from the cardiac myocytes in the hearts of $\mathbf{J}$ group compared with those of $\mathbf{C}$ group. CPK activity was measured in the coronary effluent for 60 minutes after reperfusion. ${ }^{*} \boldsymbol{P}<.05$. All values are expressed as means \pm SEM.

CPK leakage of the coronary effluent was significantly lower in the $\mathrm{J}$ group compared with that in the $\mathrm{C}$ group (2.9 \pm 2.0 vs $1.4 \times 10^{2} \pm 61 \mathrm{IU} / 60$ minutes, $P<.05$, Figure 2 ).

\section{Myocardial Water Content}

No significant difference of the myocardial water content was found between the 2 groups ( $\mathrm{J}$ group: $80 \% \pm 2 \%$ vs $\mathrm{C}$ group: $81 \% \pm 2 \%$ ).

\section{Tissue Amounts of Inflammatory Cytokines}

The tissue level of TNF- $\alpha$ was significantly lower in the $\mathrm{J}$ group compared with that in the $\mathrm{C}$ group $\left(2.4 \pm 0.3 \times 10^{2}\right.$ vs $5.5 \pm 0.8 \times 10^{2} \mathrm{pg} / \mathrm{mg}$ tissue, $P<.05$; Figure $\left.3, A\right)$. The tissue level of IL- 6 was significantly lower in the $\mathrm{J}$ group compared with that in the $C$ group $(60 \pm 7$ vs $3.0 \pm 0.8 \times$ $10^{2} \mathrm{pg} / \mathrm{mg}$ tissue, $P<.05$; Figure $\left.3, B\right)$. The tissue level of IL-8 was significantly lower in the $\mathrm{J}$ group compared with that in the $C$ group $\left(68 \pm 19\right.$ vs $2.4 \pm 0.4 \times 10^{2} \mathrm{pg} / \mathrm{mg}$ tissue, $P<.05$; Figure $3, C$ ). The tissue level of IL- $1 \beta$ was lower in the $\mathrm{J}$ group compared with that in the $\mathrm{C}$ group (2.6 $\pm 0.2 \times 10^{3}$ vs $3.7 \pm 0.7 \times 10^{2} \mathrm{pg} / \mathrm{mg}$ tissue; Figure $3, D$ ).

\section{Discussion}

In the present report we showed a cardioprotective effect of pharmacologic preconditioning with JTE-607, a novel cytokine synthesis inhibitor. The recovery of cardiac function of hearts after reperfusion was significantly better in the JTE-607 preconditioning group. In addition, the JTE-607 preconditioning group showed significantly lower levels of 

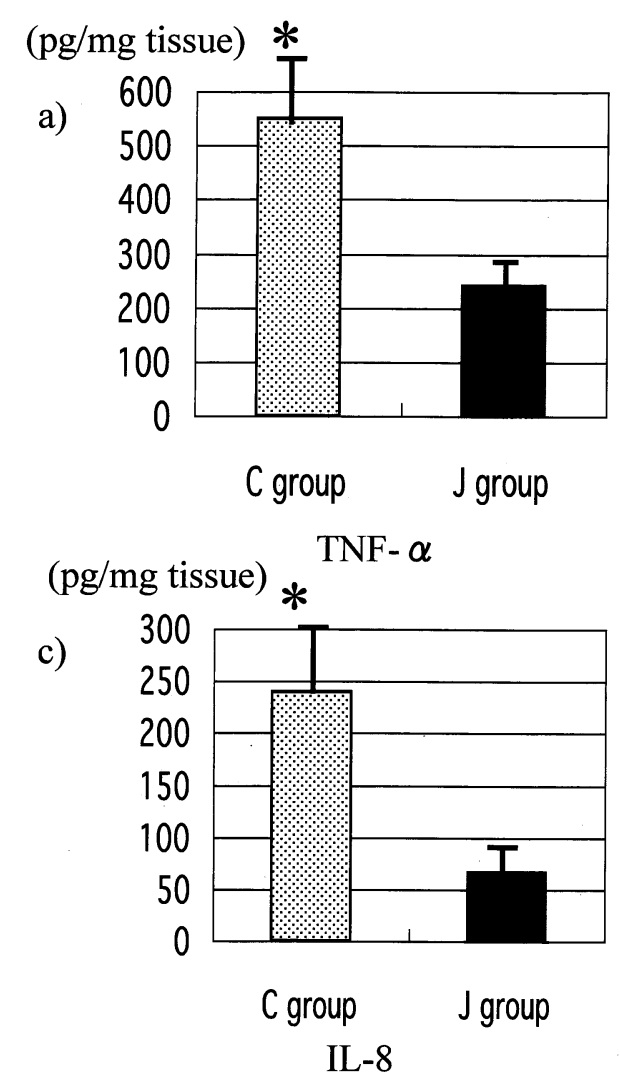
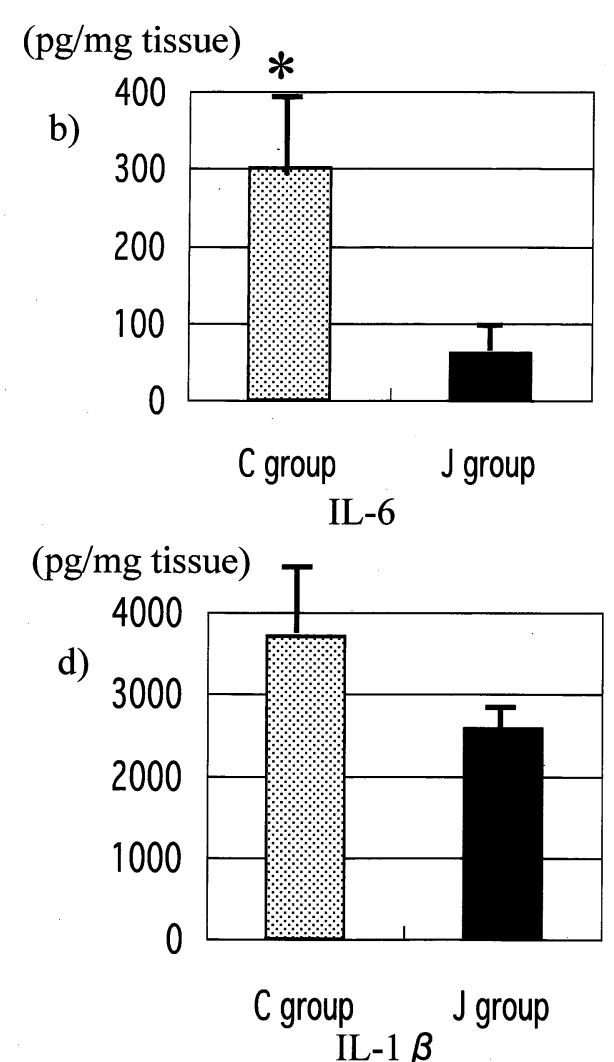

CPK leakage of coronary flow and significantly lower levels of tissue inflammatory cytokines (TNF- $\alpha$, IL-6, and IL-8). These data were not influenced by myocardial edema because no significant difference was found in the myocardial water content. These results suggested that the pharmacologic preconditioning of JTE-607 inhibits a burst of cytokines in the myocardium, resulting in the attenuation of ischemia-reperfusion injury.

Although previous studies have shown that proinflammatory cytokines have direct effects for the decrease of myocardial contractility, ${ }^{7,8}$ the characteristics of each cytokine to the myocardium widely differ. IL- $1 \beta$ was shown to blunt the positive inotropic response to isoproterenol in neonatal cardiac myocytes but in the delayed phase (72 hours). ${ }^{9}$ IL-6 had been considered to have negative inotropic effects on the basis of evidence of increased level of IL-6 linked to cardiac dysfunction after cardiopulmonary bypass, ${ }^{10-12}$ but recently, IL-6 has been considered to be a marker rather than a critical mediator of myocardial injury. ${ }^{13}$ IL-8 is known to be a potent chemoattractant for neutrophils to induce reperfusion injury, ${ }^{14,15}$ but no evidence has been reported that IL- 8 in itself has an effect for myocardial contractility. As opposed to these proinflammatory cytokines, TNF- $\alpha$ can induce myocardial decrease within minutes through the production of sphingosine, ${ }^{16}$ a depressant of calcium transient in the myocardium. Moreover, TNF- $\alpha$ was shown to be induced by ischemia-reperfusion injury in the crystalloid-perfused heart, ${ }^{17}$ and the origin of this cytokine suggested that it is derived from resident monocytes-macrophages in the myocardium or the myocyte itself. ${ }^{18}$ Together with this evidence and our results on the immediate effect of JTE-607 in the crystalloidperfused heart, the supposed mechanism of the cardioprotective effect of JTE607 might be mainly the inhibition of TNF- $\alpha$ derived from resident monocytes-macrophages in the myocardium or the myocyte. Further in vitro study will be needed to confirm this mechanism.

Although we demonstrated that the inhibition of myocardial tissue cytokine can improve function, it does not reflect in vivo conditions in many ways. Because this heart model is perfused with crystalloid and not blood, aspects of blood that are either protective (ie, antioxidant) or injurious (ie, neutrophils and blood-derived cytokines) do not contribute. ${ }^{17}$ Indeed, we have already performed a blood per- 
fusion model with a rat cardiopulmonary bypass model and found significant improvement of respiratory function and the significant inhibition of blood IL-8 after cardiopulmonary bypass by means of the injection of JTE-607 (unpublished data). After coupling these results and our findings, it is suggested that JTE-607 might be effective for cardiac surgery by inhibiting proinflammatory cytokines both in the myocardium and in the blood. Therefore further studies are required to examine the cardioprotective effect of JTE- 607 with a blood-perfused ischemia-reperfusion model to investigate how JTE-607 influences the factors in the blood. In conclusion, we obtained evidence that JTE-607 attenuates myocardial ischemia-reperfusion injury through inhibition of synthesis of inflammatory cytokines. Thus JTE-607 might be a novel therapeutic strategy for the protection of postoperative cardiac dysfunction in cardiovascular surgery.

We thank Hiromitsu Watanabe (Japan Tobacco Inc) for providing current data and information about JTE-607.

\section{References}

1. Ueda H, Sawa Y, Matsumoto K, Kitagawa-Sakakida S, Kawahira Y, Nakamura T, et al. Gene transfection of hepatocyte growth factor attenuates reperfusion injury in the heart. Ann Thorac Surg. 1999;67: 1726-31.

2. Kawamura T, Nara N, Kadosaki M, Inada K, Endo S. Prostaglandin E1 reduces myocardial reperfusion injury by inhibiting proinflammatory cytokines production during cardiac surgery. Crit Care Med. 2000;28: 2201-8.

3. Cain BS, Meldrum DR, Dinarello CA, Meng X, Joo KS, Banerjee A, et al. Tumor necrosis factor- $\alpha$ and interleukin- $1 \beta$ synergistically depress human myocardial function. Crit Care Med. 1999;27(7):130918.

4. Yoshiki S, Yasuhisa S, Keishi K, Takashi M, Hirotsugu F, Toshihiro $\mathrm{O}$, et al. Attenuation of cardiopulmonary bypass derived inflammatory reactions reduces myocardial reperfusion injury in open heart surgery. Jpn Pharmacol Ther. 1995;23:123-7.

5. Kakutani M, Takeuchi K, Iwamura H, Wakitani K. JTE-607, a novel inflammatory cytokine synthesis, inhibitor without immunosuppres- sion, protects from endotoxin shock in mice. Inflamm Res. 1999;48: 461-8.

6. Iwamura H, Inushima $\mathrm{K}$, Takeuchi $\mathrm{K}$, Kakutani $\mathrm{M}$, Wakitani $\mathrm{K}$. Prophylactic effect of JTE-607 on LPS-induced acute lung injury in rats with CINC-1 inhibition. Inflamm Res. 2002;51:160-6.

7. Mann DL. Stress-activated cytokines and the heart: from adaptation to maladaptation. Anпи Rev Physiol. 2003;65:81-101.

8. Wan S, Yim AP. Cytokines in myocardial injury: impact on cardiac surgical approach. Eur J Cardiothorac Surg. 1999;16(suppl 1):S10711.

9. Gulick TS, Chung MK, Pieper SJ, Lange LG, Schreiner GF. Interleukin 1 and tumor necrosis factor inhibit cardiac myocyte $\beta$-adrenergic responsiveness. Proc Natl Acad Sci U S A. 1989;86:6753-57.

10. Sawa Y, Ichikawa H, Kagisaki K, Ohata T, Matsuda H. Interleukin-6 derived from hypoxic myocytes promotes neutrophil-mediated reperfusion injury in myocardium. J Thorac Cardiovasc Surg. 1998;116(3): 511-7.

11. Hennein HA, Ebba H, Rodriguez JL, Merrick SH, Keith FM, Bronstein $\mathrm{MH}$, et al. Relationship of the proinflammatory cytokines to myocardial ischemia and dysfunction after uncomplicated coronary revascularization. J Thorac Cardiovasc Surg. 1994;108(4):626-35.

12. Deng MC, Dasch B, Erren M, Mollhoff T, Scheld HH. Impact of left ventricular dysfunction on cytokines, hemodynamics, and outcome in bypass grafting. Ann Thorac Surg. 1996;62(1):184-90.

13. Wan S, LeClerc JL, Vincent JL. Cytokine responses to cardiopulmonary bypass: lessons learned from cardiac transplantation. Ann Thorac Surg. 1997;63(1):269-76.

14. Ivey CL, Williams FM, Collins PD, Jose PJ, Williams TJ. Neutrophil chemoattractants generated in two phases during reperfusion of ischemic myocardium in the rabbit. Evidence for a role for $\mathrm{C} 5 \mathrm{a}$ and interleukin-8. J Clin Invest. 1995;95(6):2720-8.

15. Kukielka GL, Smith CW, LaRosa GJ, Manning AM, Mendoza LH, Daly TJ, et al. Interleukin-8 gene induction in the myocardium after ischemia and reperfusion in vivo. J Clin Invest. 1995;95(1):89-103.

16. Oral H, Dorn GW 2nd, Mann DL. Sphingosine mediates the immediate negative inotropic effects of tumor necrosis factor-alpha in the adult mammalian cardiac myocyte. J Biol Chem. 1997;272(8):483642.

17. Meldrum DR, Cleveland JC Jr, Cain BS, Meng X, Harken AH. Increased myocardial tumor necrosis factor-alpha in a crystalloidperfused model of cardiac ischemia-reperfusion injury. Ann Thorac Surg. 1998;65(2):439-43.

18. Kapadia S, Lee J, Torre-Amione G, Birdsall HH, Ma TS, Mann DL. Tumor necrosis factor-alpha gene and protein expression in adult feline myocardium after endotoxin administration. J Clin Invest. 1995; 96(2):1042-52. 